
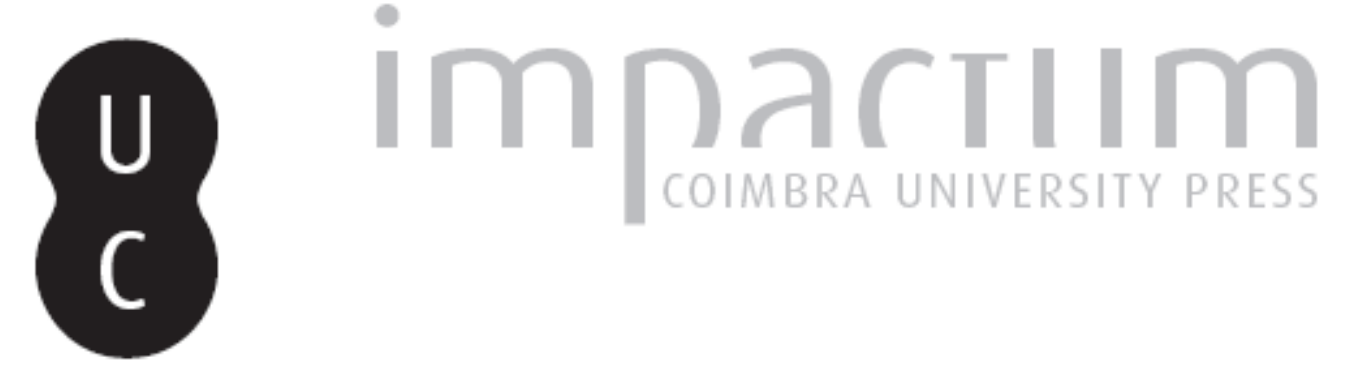

\title{
Considerações sobre riscos naturais num espaço de transição: exercícios cartográficos numa área a Sul de Coimbra
}

Autor(es): $\quad$ Cunha, Lúcio; Dimuccio, Luca

Publicado por: Associação Portuguesa de Riscos, Prevenção e Segurança

URL persistente:

URI:http://hdl.handle.net/10316.2/40085

DOI:

DOI:https://doi.org/10.14195/1647-7723_9_3

Accessed : $\quad$ 26-Apr-2023 10:42:16

A navegação consulta e descarregamento dos títulos inseridos nas Bibliotecas Digitais UC Digitalis, UC Pombalina e UC Impactum, pressupõem a aceitação plena e sem reservas dos Termos e Condições de Uso destas Bibliotecas Digitais, disponíveis em https://digitalis.uc.pt/pt-pt/termos.

Conforme exposto nos referidos Termos e Condições de Uso, o descarregamento de títulos de acesso restrito requer uma licença válida de autorização devendo o utilizador aceder ao(s) documento(s) a partir de um endereço de IP da instituição detentora da supramencionada licença.

Ao utilizador é apenas permitido o descarregamento para uso pessoal, pelo que o emprego do(s) título(s) descarregado(s) para outro fim, designadamente comercial, carece de autorização do respetivo autor ou editor da obra.

Na medida em que todas as obras da UC Digitalis se encontram protegidas pelo Código do Direito de Autor e Direitos Conexos e demais legislação aplicável, toda a cópia, parcial ou total, deste documento, nos casos em que é legalmente admitida, deverá conter ou fazer-se acompanhar por este aviso.

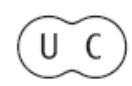




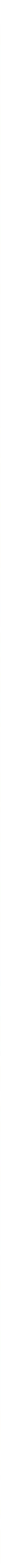




\title{
Considerações sobre riscos naturais num espaço de transição. Exercícios cartográficos numa área a Sul de Coimbra*
}

\author{
Lúcio Cunha** \\ Luca Dimuccio"*-
}

\section{Resumo:}

Após algumas considerações sobre riscos naturais na área de Coimbra, pretende-se explorar as potencialidades dos Sistemas de Informação Geográfica (SIG's) para modelizar e cartografar o risco de movimentos de materiais em vertentes numa pequena área a Sul da cidade.

\section{Palavras-chave:}

Riscos Naturais; Riscos Geomorfológicos; Coimbra; Sistemas de Informação Geográfica (SIG's)

\section{Résumé:}

Après quelques considérations autour des risques naturels dans la région Coimbra, nous projetons d'explorer les potentialités des Systèmes d'Information Géographique (SIG's) afin de modeler et de cartographier les mouvements de versant dans une petite région au sud de la ville.

Mots clés :

Risques Naturels ; Risques Géomorphologiques ; Coimbra ; Systèmes d'Information Géographique (SIG's)

\section{Abstract:}

After some considerations about natural risks in the Coimbra area, we intend to explore the Geographic Information System (GIS) potentialities for modelling and mapping slope movements at a small south area of the town.

Key words:

Natural Risks; Geomorphologic risks; Coimbra; Geographic Information System (GIS)

\section{Introdução}

As transformações económicas, sociais e culturais verificadas ao longo do século passado e, particularmente, o processo crescente de globalização das economias e das culturas que se traduzem numa Geografia Nova à escala global, ficam também marcadas por fortes pressões sobre o ambiente e por marcas, muitas

\footnotetext{
Este texto tem por base duas comunicações apresentadas em reuniões científicas na Universidade de Coimbra. A primeira, apresentada ao III Colóquio de Geografia de Coimbra (15 e 16 de Março de 2001), teve por Autores Lúcio CUNHA, Helena ALBUQUERQUE, Luca DIMUCCIO e Luis FIGUEIRA e intitulava-se "Sistemas de Informação Geográfica e Cartografia de Riscos Naturais - um exemplo na área a Sul de Coimbra"; a segunda, apresentada pelos signatários ao VII Encontro de Riscos Naturais (19 de Outubro de 2001) teve como título "Considerações sobre riscos naturais num espaço de transição. Breve análise das cheias e movimentos de materiais em vertentes no Inverno de 2000-2001 em
}

vezes irreparáveis, sobre alguns territórios. Nos países menos desenvolvidos, a delapidação dos recursos naturais, a fome, o uso e abuso de tecnologias ultrapassadas e a consequente poluição ambiental; nos países mais desenvolvidos, a poluição decorrente de processos desarticulados de produção agrícola, energética e industrial, de consumo e de transportes; nuns e noutros uma crescente procura dos espaços urbanos, que conjugada com a falta de políticas

Coimbra". O texto que agora se apresenta corresponde à síntese do trabalho que tem vindo a ser desenvolvido, cumprindo-nos agradecer a Helena ALBUQUERQUE o entusiasmo e saber que colocou nas primeiras experiências de trabalho sobre Sistemas de Informação Geográfica. Agradecemos-lhe ainda, assim como a Luís FIGUEIRA, toda a colaboração e o empenho no trabalho de campo realizado.

** Centro de Estudos Geográficos. Faculdade de Letras da Universidade de Coimbra.

*** Bolseiro da Fundação para a Ciência e Tecnologia. 
ajustadas de ordenamento do território, levam a um crescendo de problemas ambientais, com particular destaque para os que se prendem com os riscos naturais e a segurança das populações.

Tambémnocaso português, em que os progressivos fenómenos de terciarização económica e social das populações estão associados à litoralização e à urbanização do território, em quase todos os espaços urbanos, sub-urbanos e peri-urbanos são visíveis as marcas da enorme pressão do Homem sobre o Ambiente, sendo muitas as imagens de degradação ambiental e da inerente perda de qualidade de vida das populações (CUNHA e CRAVIDÃO, 2001). Destas imagens assumem particular importância as que se ligam às cheias e inundações de muitas das cidades ribeirinhas e aos movimentos de materiais em vertentes, responsáveis pela destruição de habitações, pelo corte de estradas e vias férreas e mesmo pela perda de vidas humanas. Pelos seus reflexos económicos, pelos impactes psicológicos e sociais que produzem na vida das populações ou, mesmo, pela multiplicidade de questõés económicas, sociais e políticas que a sua gestão envolve, os chamados "riscos naturais" são, hoje, um tema incontornável nos estudos sobre a cidade e sobre a qualidade de vida urbana.

\section{Alguns problemas conceptuais e terminológicos}

Apesar de ser matéria de tratamento recente, pelo menos comesta formulação e com utilização explícita da expressão "riscos naturais", são já muitos os estudos que no nosso país foram feitos por geógrafos, geólogos, engenheiros e outros investigadores. De entre eles, destacamos pelo seu interesse teórico os trabalhos de A. B. FERREIRA (1992), J.Luís ZÊZZERE (1997 e 2001), L. RODRIGUES (1998), F. REBELO (1999 e 2001) e A. TAVARES (1999).

De um modo talvez muito simplista, podemos dizer que, com base na conhecida fórmula que traduz a noção compósita do risco ${ }^{(1)}$, o estudo dos riscos naturais implica a análise integrada de dois conjuntos de factores, os factores ligados à dinâmica natural do Meio, que configuram o conceito de hazard, para os cientistas de língua inglesa, e de aléas para os de língua francesa ${ }^{(2)}$, e os factores ligados à diferente

(1) $R=A+V$, para os autores de língua francesa ou $R=H+V$ para os de língua inglesa (F. REBELO, 1999). No entanto, a combinação entre o factor Aléas (ou Hazard) e o factor vulnerabilidade talvez traduza melhor o conceito de risco natural se estes forem relacionados através do operador multiplicação $\mathrm{R}=\mathrm{A} \times \mathrm{V}$ ou $\mathrm{R}=\mathrm{H} \times \mathrm{V}$, ou simplesmente através do operador função $[R=F(A, V)$ ou $R=F(H, V)]$ definido caso a caso, como refere, por exemplo. André DAUPHINÉ (2001).

(2) Perigosidade, ou qualidade de perigo, talvez fosse a tradução mais ajustada em português, à semelhança do que se passa com as traduções para língua espanhola ou italiana (ZÉZERE. 2001, p. 129).

No entanto, alguns Autores como, por exemplo, F. REBELO (1999) preferem reservar o termo perigo para ser utilizado no contexto da vulnerabilidade das populações, decorrente não só das características demográficas, mas sobretudo do seu poder económico, do seu modo de organização política ou do seu estatuto social e cultural. Curiosamente, tanto nuns como noutros, o Homem marca a sua presença, diríamos mesmo é determinante para as transformações responsáveis por um aumento significativo do risco em determinados territórios (CUNHA e CRAVIDÃO, ob. cit.).

Enquanto conceito entendido no seu sentido mais restrito, hazard ou aléas designa a probabilidade espacial e temporal de ocorrência de um fenómeno, neste caso um fenómeno indesejado, pelas consequências negativas de que se reveste para o Homem e para a sociedade. Essa probabilidade decorre, naturalmente, das condições dinâmicas do meio físico-natural e estas têm vindo a sofrer alterações profundas em consequência de transformações impostas pelo uso social do territória. Poderíamos começar pela tão propalada transformação climática global, hoje frequentemente invocada como justificação à escala planetária para muitos dos erros de gestão territorial realizados à escala local e regional. Poderíamos também apontar as modificações decorrentes da regularização dos cursos de água (barragens, açudes, obras de regadio e enxugo), do êxodo rural e do abandono dos campos agrícolas (socalcos sem tratamento e conservação, por exemplo), da transformação da mancha florestal (plantação maciça de pinheiros e, mais recentemente, de eucaliptos, em matas mono-específicas, que substituíram progressivamente as florestas autóctones) ou da modificação do traçado e da dinâmica da linha de costa. A uma escala mais local, e particularmente em meio urbano, estas transformações decorrem, sobretudo da alteração das condições superficiais do terreno (destruição do coberto vegetal, impermeabilização de vastas superfícies; encanamento e, mesmo, obstrução de linhas de água; alteração da morfologia superficial de pormenor) e a decorrente alteração das condições de drenagem superficial e subterrânea, da modificação das cargas sobre as unidades litológicas e sobre as vertentes e taludes, em função da construção de habitações e infra-estruturas, entre outras. Nos espaços envolventes das cidades, os terrenos agrícolas deixam de cumprir a sua função secular e são propositadamente abandonados e votados a uma lenta espera por processos de mera especulação imobiliária.

sequência Risco - Perigo - Crise, estabelecida de acordo com trabalhos patrocinados pela UNESCO (1987 e 1989) e, particularmente. do trabalho teórico desenvolvido por L. FAUGÈRES (1990). Neste caso o termo Hazard teria um significado muito próximo do de risco, devendo ser este o termo apropriado em termos de tradução.

Por outro lado, a própria evolução conceptual do termo hazard, que terá começado por se aproximar do conceito de risco, para mais tarde ir ganhando um significado mais restrito que o aproxima do conceito de aléas, aliada à conotação essencialmente fatalista do termo leva autores como DAUPHINÉ (ob. cit., p. 30) a propor, dada a actual polissemia do conceito, o abandono do uso deste temo. 
Por outro lado, o conceito de vulnerabilidade procura traduzir as consequências previsíveis, sobre o homem e a sociedade, de um fenómeno natural. Pode ser avaliada de diferentes modos, desde o valor económico-financeiro dos prejuízos (análise custobeneficio) e a quantidade de energia necessária para reparar as perdas e danos, às chamadas técnicas multicritério em que se conjugam diversos destes elementos (DAUPHINÉ, 2001). Os fenómenos de concentração urbana, com crescimento desordenado das cidades e a transformação do espaçorural envolvente num imenso e descaracterizado subúrbio, são responsáveis por um acréscimo do factor vulnerabilidade, particularmente para as populações urbanas de mais baixos rendimentos. Alguns exemplos: o inadequado traçado de muitas vias de comunicação; a construção indevidamente acautelada em vertentes com declives acentuados ou nos leitos de inundação dos rios; os desequilíbrios económicos e sociais, com aparecimento de fenómenos de exclusão bem traduzidos nas fragilizadas condições de habitação de alguns bairros sociais, na persistência de "barracas" nas cidades, mesmo no chamado mundo desenvolvido, ou na utilização, em muito más condições de habitabilidade e segurança, de habitações antigas e degradadas dos muitos centros históricos; finalmente, a diferenciação de capacidade financeira e a desigualdade no acesso aos serviços de saúde e educação, à informação e à cultura são também, para muitos, factores de vulnerabilidade que importaria considerar.

Deveremos ou poderemos analisar isoladamente estes dois factores?

Do ponto de vista analítico, talvez sim! No caso específico do tratamento cartográfico do risco de movimentação de materiais em vertentes, através de Sistema de Informação Geográfica, a que nos propomos neste trabalho, pareceria mesmo absolutamente necessária a individualização destes dois grupos de factores: os factores que comandam a dinâmica de vertentes na área e os factores que justificam a diferenciação das vulnerabilidades das populações directa ou indirectamente implicadas, ainda que estes sejam de difícil quantificação e de ainda mais difícil representação.

$\mathrm{Na}$ opinião de F. REBELO (ob. cit.) a actual distribuição do Homem no Planeta e o carácter indirecto de muitos dos efeitos dos fenómenos naturais fazem com que "a vulnerabilidade esteja sempre presente" e, por consequência, orisco também. Assim "a vulnerabilidade é intrínseca à noção de risco e quase não se vê a necessidade de falar em aleatório, acaso, casualidade ou perigosidade". Neste caso, a fórmula compósita do risco deixaria de ter pleno significado, ainda que possa ser aceite "só por uma questão de metodologia" que permita jogar com diversos graus de vulnerabilidade.
Seja como for, o risco terá sempre uma dimensão probabilística, de algum modo próxima de um sentimento de incerteza, ainda que não de fatalidade ${ }^{(3)}$, diferentemente sentida e percebida pela população em função do tempo histórico, mas também do estatuto económico, social e cultural, e em função de outros dados demográficos, como o sexo e a idade, ou geográficos, como o local de naturalidade, residência ou vivência (TELES, 2001; SANTOS et al., 2001). Neste processo perceptivo de grande importância em termos de Ordenamento do Território, sobretudo à escala local, dada, por exemplo, a diferente valorização dos espaços e, particularmente, dos solos urbanos e peri-urbanos, têm particular importância os diferentes estudos técnico-científicos sobre o tema, mas também, e sobretudo, o modo como os meios de comunicação social perturbam essa percepção, por exemplo ao condicionar a relevância de acidentes e catástrofes naturais em função do contex to noticioso do momento.

\section{Sistemas de informação Geográfica e análise de riscos naturais}

Um Sistema de Informação Geográfica (SIG) pode ser entendido como um "conjunto articulado de Hardware e Software capaz de desempenhar funções diversas, nomeadamente a captura, organização, manipulação, análise, modelação e apresentação de dados espacialmente referenciados e destina-se a resolver problemas complexos de planeamento e gestão" (RAPER, 1991, citado por João MACHADO, 1999, p. 240). Segundo alguns autores, a definição deSIG não estará completa se nela não forem integradas as bases de dados utilizadas e o contex to operacional ou organizacional em que se opera, ou seja, para além das máquinas, programas e dados, importará também considerar, os objectivos de trabalho e o grupo de pessoas que gere e utiliza o sistema (CNIG, 1992, citado por Pedro NETO, 1998, p. 14).

A evolução recente e, particularmente, o aparecimento no mercado de software cada vez poderoso em termos de cálculo, mas também de utilização mais amigável (caso do programa Arc View), é responsável por um acréscimo significativo da popularidade destas ferramentas entre geógrafos e outros investigadores que trabalham sobre o espaço e o território. Nos últimos anos intensificou-se o ensino das técnicas de operação com SIG's, tanto nos cursos de Geografia, como fora deles e, a par disso, vulgarizou-se a utilização destas poderosas ferramentas na elaboração de cartografia temática e na própria análise geográfica, através do cruzamento e tratamento matemático de informação espacial georreferenciada.

(3) De certa forma associada ao conceito de Hazard (DAUPHINÉ, 2001, p. 30) 
Pela diversidade dos elementos em jogo, pela complexidade das relações que entre eles se estabelecem e, sobretudo, pelo carácter espacial de que se revestem, os estudos ambientais são uma das áreas em que os SIG's têm particular interesse, enquanto ferramenta de análise. É, particularmente, o caso do estudo dos riscos naturais. Com base em ferramentas SIG é possível não só manter actualizada a cartografia das áreas afectadas por acidentes e catástrofes naturais, como criar modelos prospectivos com base no cruzamento e tratamento quantitativo dos factores intervenientes (por exemplo: relevo, geologia, uso do solo, elementos climáticos, dados demográficos, infra-estruturas, para previsão do risco de movimento de materiais em vertentes ou de cheias rápidas e inundação).

No caso em análise neste trabalho pretende-se, através da utilização do software Arc View 3.2, discutir a criação de diferentes tipos de modelos para análise da distribuição espacial de movimentos de materiais nas vertentes numa pequena área a Sul de Coimbra.

\section{Coimbra - um espaço de transição}

Situada num espaço de transição entre o Norte e o Sul e entre o Interior e o Litoral de Portugal, servida por um eixo fundamental que é o do maior rio nacional, Coimbra deve a esta sua posição natural privilegiada grande parte da evolução histórica que lhe conferiu a importância que actualmente assume no plano urbano português.

No entanto, esta posição privilegiada tem algumas implicações no funcionamento dos sistemas naturais. O confronto entre as baixas terras litorais da Orla Mesocenozóica Ocidental (planície aluvial e colinas gresosas e calcárias) com as serras e planaltos do Maciço Hespéricoé responsável, na área de Coimbra, pela existência de um quadro litológico e estrutural extremamente diversificado (SOARES et al., 1985; SOARES, 1990, TAVARES, 1999), por uma morfologia vigorosa e contrastada (REBELO, 1985, ALMEIDA et al., 1990, CUNHA et al., 1997, CUNHA e SOARES, 1997), com declives acentuados, frequentemente acima dos $30^{\circ}$ nas vertentes do Maciço Marginal de Coimbra, por condições climáticas particulares que passam, nomeadamente, pelo reforço orográfico das perturbações pluviosas de Oeste e Noroeste e, naturalmente, por um quadro de múltiplas formas de utilização do solo, que vai das férteis terras agrícolas da planície aluvial às monótonas matas de pinheiros e eucaliptos com que foram arborizadas as vertentes do Maciço Marginal.

Apesar da sua condição de cidade média, com pouco mais de 100000 habitantes no ano de 2001, Coimbra tem vindo a assistir a um processo fortemente especulativo de procura de residência e de consequente pressão șobre os solos urbanos e urbanizáveis, o que em muito tem contribuído para um alastrar da mancha urbana para fora do espaço consolidado da cidade. Este processo que, na maior parte das vezes, parece responder mais a interesses individuais de sabor especulativo que ao cumprimento de planos e projectos municipais traduz-se, em regra, por uma utilização indevida ou, pelo menos, inadequada do espaço que, para além dos inevitáveis custos infra-estruturais, tem consequências em termos da susceptibilidade do território aos diferentes fenómenos naturais e, portanto dos riscos naturais.

Na diversidade do quadro geográfico assentam muito dos factores considerados por F. REBELO (1999) naquilo que chamou a "Bacia de riscos de Coimbra". Na área de Coimbra convergem riscos de natureza hidrológica, associados às históricas cheias do Mondego (A. F. MARTINS, 1940; F. REBELO, 1995; R.SANCHES, 1996), não totalmente debeladas após as obras de regularização dos anos 70 , riscos de natureza geomorfológica associados a diversos tipos de movimentos materiais em vertentes (CUNHA e ROCHA, 1997; TAVARES, 1999; LOURENÇO e LEMOS, 2001), risco de incêndio florestal e, pelo menos até há muito pouco tempo, poder-se-ia mesmo falar de riscos de natureza tecnólógica em virtude da decisão, recentemente abandonada, de instalar um sistema de co-incineração de resíduos perigosos na cimenteira de Souzelas $(10 \mathrm{Km}$ a Norte do centro da cidade).

\section{O carácter excepcional da queda pluviométrica no Inverno de 2000/2001}

O Inverno de 2000-2001 foi extremamente pluvioso, particularmente no Centro e Norte de Portugal. Os meses mais pluviosos foram os meses de Novembro, Dezembro, Janeiro e Março, tendo as precipitações acumuladas nos meses de Dezembroe Janeiro alcançado valores que correspondem a um período de retorno centenário (RODRIGUES, BRANDÃO E COSTA, 2001). No caso de Coimbra, os valores acumulados da precipitação ocorrida nos meses de Novembro, Dezembro e Janeiro bateram todos os recordes dos registos mais que centenários da estação do Instituto Geofísico da Universidade. No entanto, analisando estes registos e, particularmente, os valores de precipitação diária (quadro I e fig. 1), sente-se claramente que nunca os valores diários terão atingido quantitativos tão elevados que justificassem de per si os movimentos de materiais em vertentes nem as brutais inundações registadas nos rios do Norte e Centro de Portugal. Já os totais mensais de Novembro, Dezembro e Janeiro foram significativos ainda que, mesmo assim, em 
nenhum deles se tenha verificado o máximo secular dos registos no Instituto. Verdadeiramente excepcionais foram a sequência de dias de chuva (72 dias, o que corresponde a $78 \%$ do total) e a soma da precipitação ocorrida no conjunto dos três meses que, essa sim, corresponde ao valor máximo registado no Instituto Geofísico da Universidade de Coimbra ao longo dos mais de 100 anos do seu funcionamento.

\begin{tabular}{|c|c|c|c|c|c|}
\hline & \multicolumn{3}{|c|}{ Out//Inv. (2000/0I) } & \multicolumn{2}{c|}{ Val. Normais (1961/90) } \\
\cline { 2 - 6 } & $\mathrm{R}(0-24)$ & $\mathrm{N}^{\circ}$ Dias & Máx.Diário & $\mathrm{R}$ & $\mathrm{N}^{\circ}$ Dias \\
\hline Setembro & 57,4 & 4 & $\mathbf{1 9 , 4}$ - dia 30 & 47,7 & 8 \\
\hline Outubro & 105,4 & 11 & $\mathbf{3 4 , 8}-$ dia 11 & 96,4 & 13 \\
\hline Novembro & 230,9 & $\mathbf{2 3}$ & $\mathbf{4 0 , 8}-$ dia 2 & 128,9 & 14 \\
\hline Dezembro & 303,4 & 26 & $\mathbf{4 3 , 8}-$ dia 5 & 129,8 & 14 \\
\hline Janeiro & 374,7 & 23 & $\mathbf{6 2 , 6}-$ dia 26 & 137,8 & $\mathbf{1 6}$ \\
\hline Set-Jan & 1071,8 & 87 & & 540,6 & 65 \\
\hline Nov-Jan & 909,0 & 72 & & $\mathbf{3 9 6 , 5}$ & $\mathbf{4 4}$ \\
\hline
\end{tabular}

Quadro I - Valores da precipitação em Coimbra de Setembro de 2000 a Janeiro de 2001. Comparação com os valorés normais.

Por esta razão os já conhecidos riscos de cheia e inundação e de movimentos de materiais em vertentes materializaram-se em vários acidentes que, não tendo tido, felizmente, tradução na perda de vidas humanas, acarretaram prejuízos avultados nos campos, em algumas infra-estruturas hidráulicas, estradas, vias férreas, estabelecimentos comerciais e habitações. Talvez as mais significativas tenham sido as cheias relativamente rápidas e as vastas inundações que ocorrerem nos dias 26 e 27 de Janeiro de 2001 em Coimbra e na planície aluvial que se situa a jusante da cidade, a fazer recordar acontecimentos frequentes na região, mas anteriores às obras de regularização terminadas em 1985. Estas obras de regularização hidráulica do Mondego têm como elemento central a Barragem da Agueira, situada cerca de $40 \mathrm{Km}$ a montante de Coimbra e a sua execução parece ter induzido em erro as populações urbanas ribeirinhas, os seus autarcas e, sobretudo, os promotores e construtores imobiliários que passaram a ocupar indevidamente o plaino aluvial, na perspectiva de que estava completamente ultrapassada a situação de risco em que este espaço se encontrava (H. CAPEL, 1973, citado por S. DAVEAU et al., 1978).

Se as inundações, e particularmente as inundações rápidas, são responsáveis por graves prejuízos económicos e pelo sentimento de forte vulnerabilidade das populações ribeirinhas, os movimentos de materiais em vertentes têm consequências em regra mais gravosas, porque menos previsíveis. No caso da cidade e da região de Coimbra, no Inverno de 2000-2001 registaram-se inúmeros casos de movimentos de materiais em vertentes, com diferentes graus de gravidade, dos quais o ocorrido no dia 27 de Dezembro e que afectou a vertente entre as ruas Alberto Jardim e a Av. Elísio de Moura (LOURENÇO e LEMOS, 2001) terá sido o mais conhecido até pelà mediatização de que foi alvo.

Estes movimentos, condicionados por um conjunto de factores naturais (litologia, estrutura, forma e dimensão das vertente, declives, exposição, cobertura vegetal e tipo de ocupação do solo, etc.), serão ou não desencadeados, sobretudo em função das condições meteorológicas e particularmente da quantidade de água que chega ao solo e permite a diminuição do atrito ou a ultrapassagem da força de coesão dos materiais. Simples quedas de blocos, desmoronamentos de terras, deslizamentos rotacionais ou translacionais,

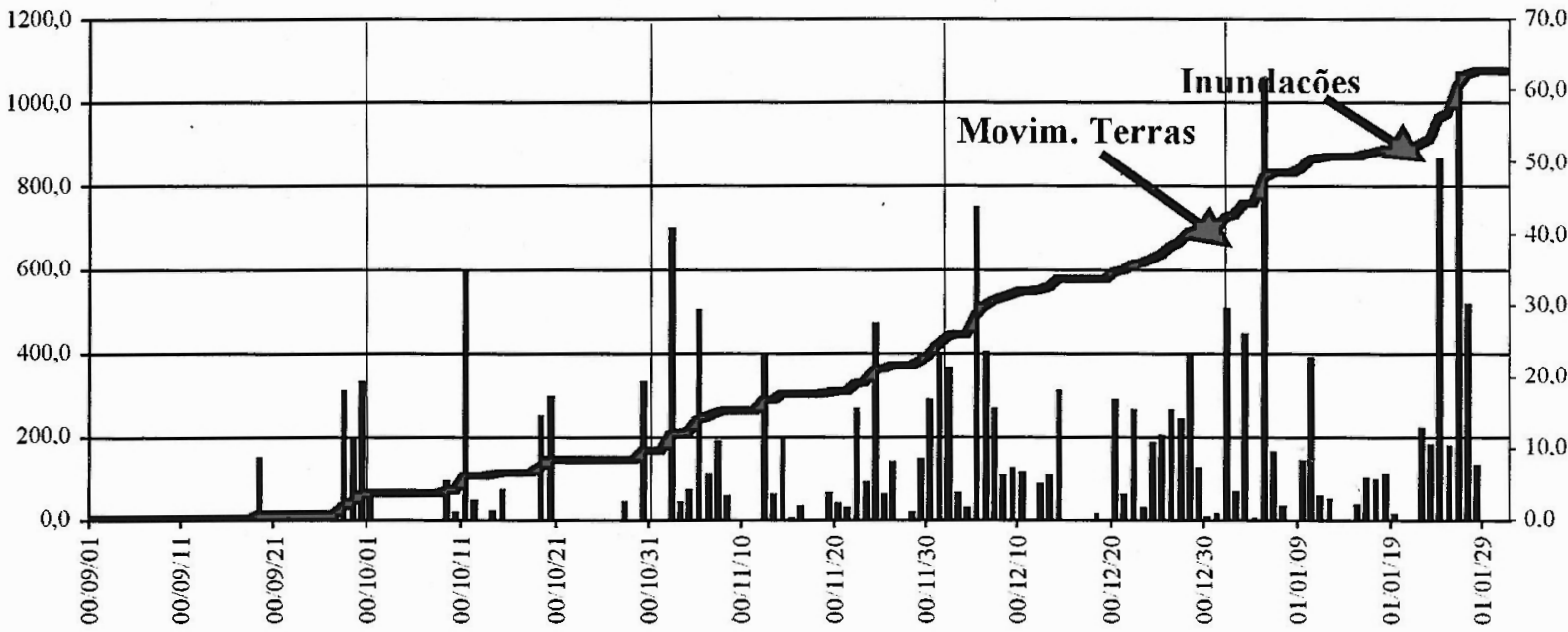

Fig. 1 - Valores diários e acumulados da precipitação em Coimbra (Setembro de 2000 a Janeiro de 2001 ). 
fluxos de detritos, terras ou lamas e movimentos complexos (em regra de associação deslizamento rotacional - "slump", com fluxos, mais ou menos lamacentos, no sector distal, os movimentos de materiais em vertentes ocorreram um pouco por todo o Norte e Centro de Portugal e, particularmente na cidade e na região de Coimbra onde, mesmo sem que tenham ocorrido acidentes fatais, perdurarão na memória das populações dados os avultados prejuízos em estradas, vias férreas e habitações.

Mas, se em Coimbra, se poderá falar, com propriedade, de acidentes, ainda que graves, noutros pontos do país aconteceram verdadeiras catástrofes. As de mais graves consequências ocorreram em Dezembro (cheias um pouco por todo o lado; movimentos de materiais em vertentes -5 mortos em Arcos de Valdevez no dia 7), Janeiro (inundações no Baixo Mondego nos dias 26 e 27 de Janeiro) e Março (54 mortos na queda da ponte de Castelo de Paiva no dia 4). No seu conjunto foi um dos Invernos mais catastróficos de que há memória. Segundo o Diário de Notícias de 17 de Outubro de 2001, contaram-se 76 mortos ( 3 dos quais na Madeira), milhares de desalojados e cerca de 100 milhões de contos (500 milhões de euros) de prejuízos.

\section{Um contributo para a cartografia de riscos de movimentação de materiais em vertentes através de SIG}

Foi a pensar no significado que o risco de movimentação de materiais em vertentes assume em termos de planeamento e ordenamento do território de áreas urbanas e peri-urbanas, particularmente numa fase em que, em Portugal, a maioria das Autarquias procede à revisão dos seus Planos Directores Municipais, que iniciámos trabalhos de cartografia de alguns elementos ligados a este tipo de riscos, usando para tal ferramentas de Sistemas de Informação Geográfica.

$\mathrm{Se}$ as áreas afectadas pelos riscos de inundação são relativamente fáceis de cartografar, dado que basicamente correspondem aos leitos de inundação dos rios, os riscos de movimentação de materiais em vertentes, e particularmente os movimentos em massa, são de cartografia mais delicada dada a complexa interacção dos factores que os favorecem, condicionam ou desencadeiam.

Seguindo de perto os modelos apresentados por L. RODRIGUES (1998), para um pequeno sector do Maciço Calcário Estremenho, e por A. TAVARES (1999), com vista à análise da susceptibilidade no espaço do concelho de Coimbra, pretendia-se, neste caso, analisar alguns dos movimentos de materiais em vertentes com consequências catastróficas registados em Coimbra e nos seus arredores e explorar as potencialidades dos SIG's (neste caso do Programa Arc View) para modelizar e cartografar o risco ${ }^{(4)} \mathrm{de}$ movimentos de materiais em vertentes numa pequena área a Sul de Coimbra.

Seleccionámos para este exercício cartográfico, uma pequena área com cerca de $18 \mathrm{Km}^{2}$ situada a Sul da cidade de Coimbra (fig. 2). Trata-se de uma área

\footnotetext{
(4) Apesar de utilizarmos a expressão "risco", trata-se apenas de um primeiro contributo para uma verdadeira cartografia de riscos que inclua, para além dos factores ligados à dinâmica do meio natural, também o tratamento efectivo dos factores ligados à vulnerabilidade das populações. Usamos o termo "risco" num sentido muito amplo, na presunção que o número e, sobretudo, a dimensão dos movimentos é proporcional aos estragos causados, num quadro que supõe, para já, uma homogeneidade artificial das condições de vulnerabilidade.
}

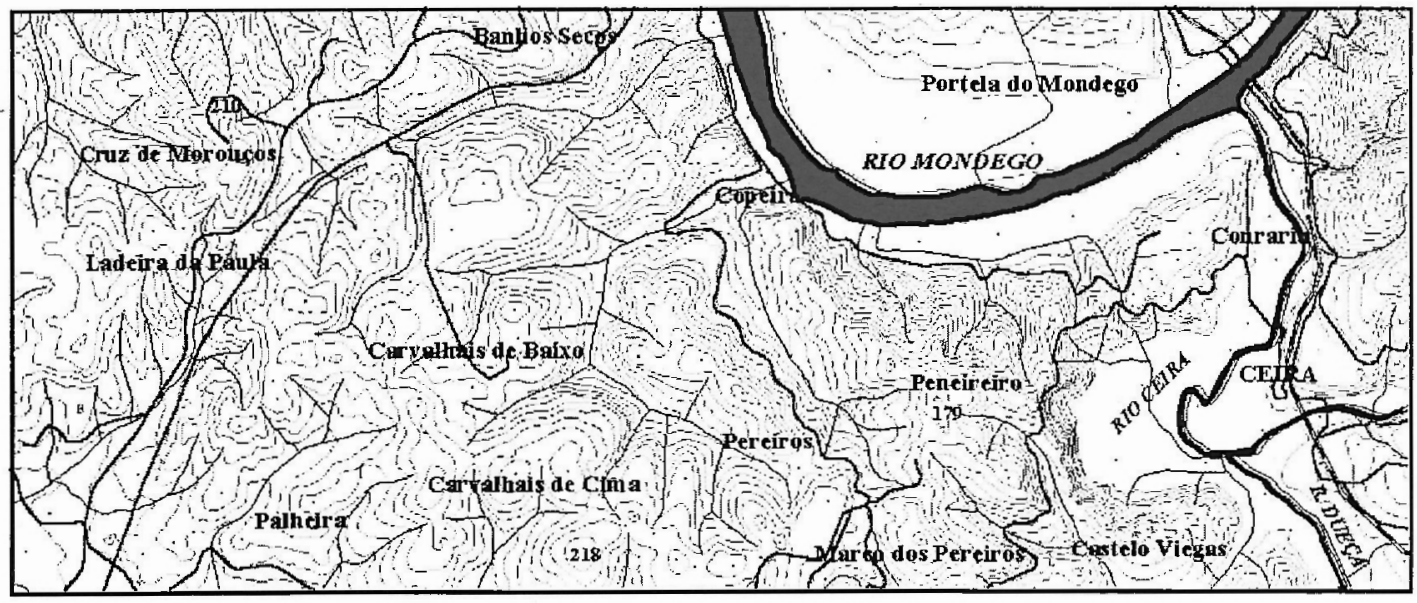

0

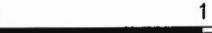

$2 \mathrm{~km}$

Fig. 2 - Localização e hipsometria da área de estudo. 
peri-urbana com características ainda marcadamente rurais, mas que aos poucos começa a sofrer os efeitos da pressão urbana na construção de imóveis, na densificação de vias de circulação e de tráfego ou tão somente no abandono e comercialização dos campos agrícolas ao sabor da especulação imobiliária. No Inverno de 2000/01 contabilizámos nesta pequena área 164 marcas de movimentos em vertentes (quadro II), que apesar das suas diferentes tipologia, dimensões e consequências, dão bem conta do carácter de forte instabilidade de uma área marcada por fortes declives, por uma grande variedade litológica e por uma quase infinita variedade de usos dos solos, aliás bem típicos destas áreas de transição.

O primeiro problema que se nos colocou relacionase com a escala de trabalho. Esta condiciona não só o tipo de dados a utilizar como, fundamentalmente, o próprio método de tratamento da informação. CARRARA et al., (1995) propõem, de acordo com as diferentes escalas de trabalho, os seguintes métodos (ver também GUZETTI et al., 1999):
- o método determinista, com criação de modelos geotécnicos, determinados caso a caso, para trabalhos a grande escala (1/2000 a 1/10000).

No presente caso, a dimensão da área a tratar, a disponibilidade da informação em formato digital e a necessidade de trabalho de campo, com vista ao reconhecimento exaustivo dos movimentos ocorridos apontam para o trabalho à escala de $1 / 25000$, o que justificaria a utilização de métodos designados como estatístico-quantitativos como aproximação ideal ao problema da cartografia de áreas de risco. No entanto, iniciaremos o tratamento usando um método qualitativo que, de algum modo, se insere nas abordagens de tipoheurístico-qualitativa, aplicáveis a escalas menores, para só depois ensaiarmos modelos de sabor mais estatístico-quantitativo, mais adaptados a escalas grandes.

A segunda questão é a da selecção dos dados a utilizar, ou seja da informação de base a introduzir

\begin{tabular}{|c|c|c|c|c|c|c|c|c|c|}
\hline & & Desliz. & Fluxo & Desab. & Rav. & $\begin{array}{c}\text { Mov. } \\
\text { Compl. }\end{array}$ & Total & Área $\left(\mathrm{Km}^{2}\right)$ & Mov $/ \mathbf{K m}^{2}$ \\
\hline Classe 1 & Calc + Calc dolom. & 5 & 4 & 1 & & & 10 & 4,35 & 2 \\
\hline Classe 2 & Xistos & 3 & 10 & 1 & & & 14 & 0,81 & 17 \\
\hline Classe 3 & Calc. Marg. + Margas & 2 & 6 & 2 & & 2 & 12 & 0,97 & 12 \\
\hline Classe 4 & Grés consol. & 16 & 58 & 3 & & 15 & 92. & 6,74 & 14 \\
\hline \multirow[t]{2}{*}{ Classe 5} & Dep. Gres. não cons. & 2 & 26 & 5 & 1 & 2 & 36 & 5,00 & 7 \\
\hline & Total: & 28 & 104 & 12 & 1 & 19 & 164 & 17,87 & 9 \\
\hline Classe 1 & Uso Florestal & 16 & 41 & 1 & & 4 & 62 & 6,63 & 9 \\
\hline Classe 2 & Cob. Arbust. c Herb. & 1 & 2 & 3 & & 0 & 6 & 0,73 & 8 \\
\hline Classe 3 & Uso Agrícola & 9 & 37 & 5 & & 13 & 64 & 8,00 & 8 \\
\hline \multirow[t]{2}{*}{ Classe 4} & Uso Urbano & 2 & 24 & 3 & 1 & 2 & 32 & 2,53 & 13 \\
\hline & Total: & 28 & 104 & 12 & 1 & 19 & 164 & 17,89 & 9 \\
\hline Classe 1 & $<5^{\circ}$ & 1 & 22 & 3 & & 5 & 31 & 6,20 & 5 \\
\hline Classe 2 & $5-15^{\circ}$ & 8 & 30 & 1 & & 4 & 43 & 7,47 & 6 \\
\hline Classe 3 & $15-30^{\circ}$ & 16 & 38 & 6 & 1 & 10 & 71 & 3,81 & 19 \\
\hline \multirow[t]{2}{*}{ Classe 4} & $>30^{\circ}$ & 3 & 14 & 2 & & & 19 & 0,39 & 49 \\
\hline & Total: & 28 & 104 & 12 & 1 & 19 & 164 & 17,87 & 9 \\
\hline
\end{tabular}

Quadro II - Tipos de movimentos de materiais em vertentes na área em estudo e sua distribuição pelas classes litológicas, de ocupação do solo e de declives.
- o método heurístico-qualitativo, mais adaptado para trabalhos a escalas médias a pequenas $(1 / 50000$ a $1 / 100000)$, em que as diferentes ponderações são o resultado de um processo empírico interactivo de análise causa-efeito entre os diferentes factores considerados e a distribuição no espaço dos movimentos;

- o método estatístico-quantitativo, para escalas médias a grandes $(1 / 25000$ a $1 / 50000)$ em que as diferentes ponderações decorrem da utilização de métodos estatísticos mais ou menos elaborados (como, por exemplo, YIN e YAN, 1988 e Van WESTEN, 1998, citados por J. L. ZÊZERE (2001) e por J. G. SANTOS (2002); no modelo. No caso em análise, com o objectivo de uma primeira aproximação à cartografia de áreas com diferentes graus de risco de movimentação de materiais em vertentes, usámos apenas três tipos de dados: declives, litologia e classes uso do solo, entendidos como os principais factores que condicionam a distribuição espacial deste tipo de movimentos ${ }^{(5)}$.

(5) A distribuição espacial e temporal deste tipo de movimentos está também relacionada com intervenções humanas sobre as vertentes que modificam as suas condições deestabilidade enquanto que, no pormenor, a distribuição temporal se prende, essencialmente, corn as condições climáticas e particularmente com os valores da precipitação que, ao modificarem as características físicas do rególito e da própria rocha-mãe, directa ou indirectamente, são responsáveis pelo desencadeamento dos movimentos. 
Temos consciência do carácter perigosamente simplista do modelo! Em primeiro lugar, considerando a noção compósita de risco atrás discutida, a abordagem efectuada apenas poderá permitir uma aproximação a uma das componentes deste conceito, já que praticamente fica de fora a componente vulnerabilidade, não sendo, nesta fase, considerados dados relativos aos quantitativos de população em risco ou ao valor económico dos terrenos, estruturas e bens eventualmente afectados pelos movimentos de materiais em vertentes. Mesmo no que respeita à componente que justifica a distribuição espacial dos movimentos, ou seja a cartografia de hazards, aléas ou "perigosidade", temos o claro sentimento de estar a reduzir em exagero as hipóteses explicativas ao considerar apenas os três factores atrás indicados. Este sentimento torna-se tanto mais incómodo quanto a possibilidade de tratamento informático de informação permitiria, com facilidade, a inclusão de um elevado número de factores explicativos, desde que estes pudessem ser traduzidos espacialmente.

No entanto, ao iniciarmos este exercício cartográfico, tomámos como objectivo claro tentar entender, as relações espaciais entre os movimentos registados e os factores que os justificavam, iniciando o estudo com um número reduzido de factores de modo a entender o peso efectivo de cada um deles na explicação.

Os declives foram estabelecidos a partir da cartografia automática derivada do mapa topográfico digital na escala de 1/25000 (fig. 2), tendo sido agrupados em 4 cląsses principais: $0-5^{\circ} ; 5-15^{\circ} ; 15-30^{\circ}$ e mais de $30^{\circ}$. A análise do mapa de declives (fig. 3) mostra claramente a importância dos declives baixos $\left(<5^{\circ}\right)$, que ocupam cerca de $35 \%$ da área, quer nos plainos aluviais dos fundos dos vales (Dueça, Ceirae Mondego), quer nos topos aplanados dos níveis de Serra da Vila $(300 \mathrm{~m})$, de Chã do Freixo $(200 \mathrm{~m})$ e de alguns pequenos terraços bem definidos nesta área (S. DAVEAU, 1985/86, L. CUNHA (1997) e J. G. SANTOS (1996); a classe de declives mais representada é a que vai dos 5 aos $15^{\circ}$ ( $42 \%$ da área), ficando a classe que vai dos 15 aos $30^{\circ}$ limitada a $21 \%$ da área. Por seu turno, os declives muito elevados ( $>30 \%$ ) que ocupam apenas $2 \%$ da área em estudo estão representados apenas nas vertentes do Maciço Marginal e, já na Orla, nas vertentes encaixadas, por vezes associadas a meandros, dos vales do Ceira e do Mondego.

Em relação à litologia foi utilizada a cartografia publicada para a área por A. TAVARES (1999). Depois de procedermos às necessárias adaptações escalåres, as unidades litológicas definidas pelos autores foram agrupadas em cinco grupos distintos tendo em vista o seu comportamento (fig. 4): Xistos $(5 \%)$, calcários e calcários dolomíticos $(24 \%)$, rochas gresosas em regra consolidadas (Grés de Silves; $38 \%$ ), rochas calcomargosas pouco resistentes $(5 \%)$ e rochas detríticas nãoconsolidadas (aluviões, depósitos de terraço e de vertente(6), depósitos cretácicos e terciários; 28\%).

(6) Apesar do extremo significado que têm os mantos de alteração superficial e os depósitos de vertente no desencadeamento de muitos dos movimentos, a dificuldade em cartografar estes elementos, pela reduzida dimensão dos afloramento, fez com que muitos deles não tivessem sido considerados.

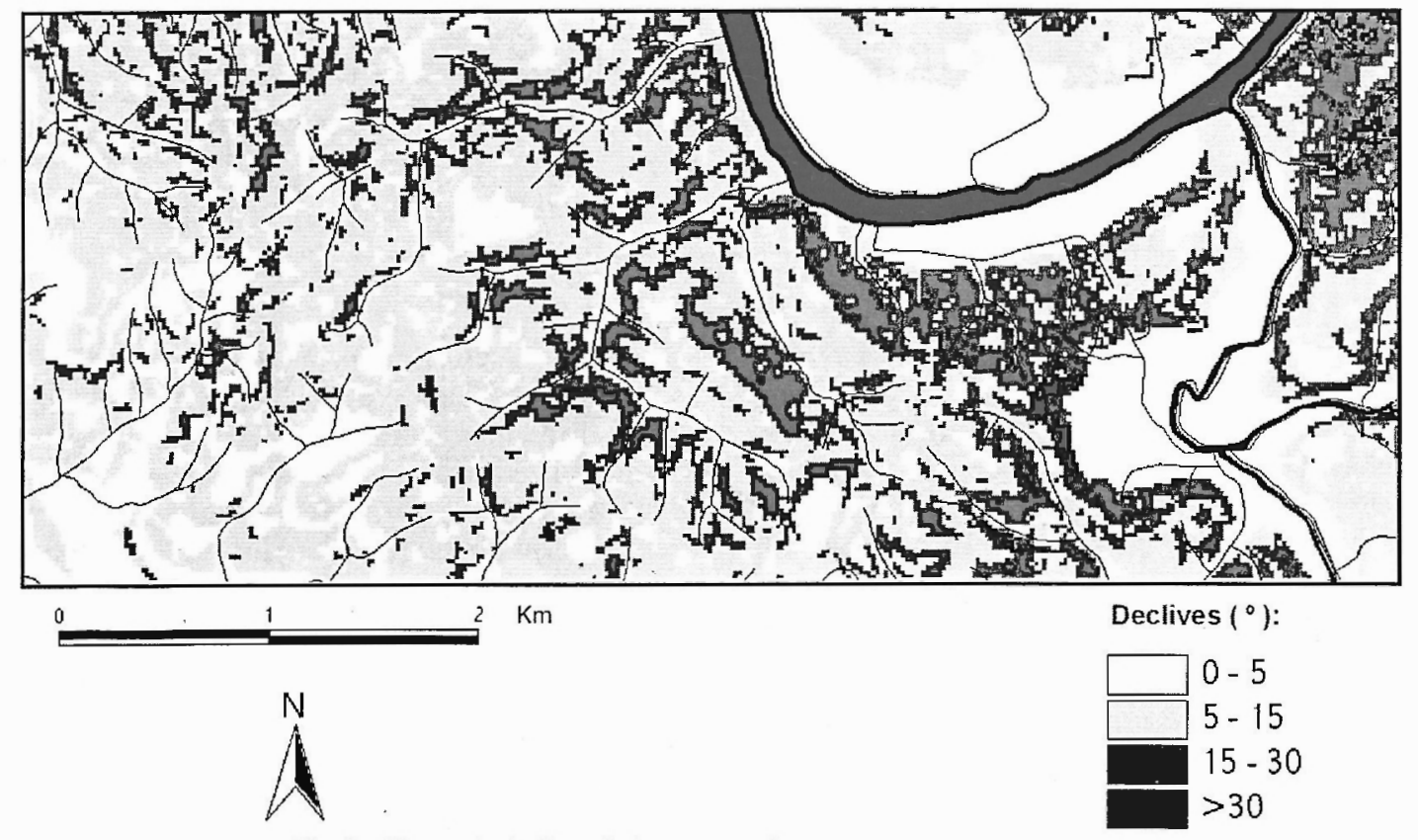

Fig. 3 - Classes de declives da área em estudo 

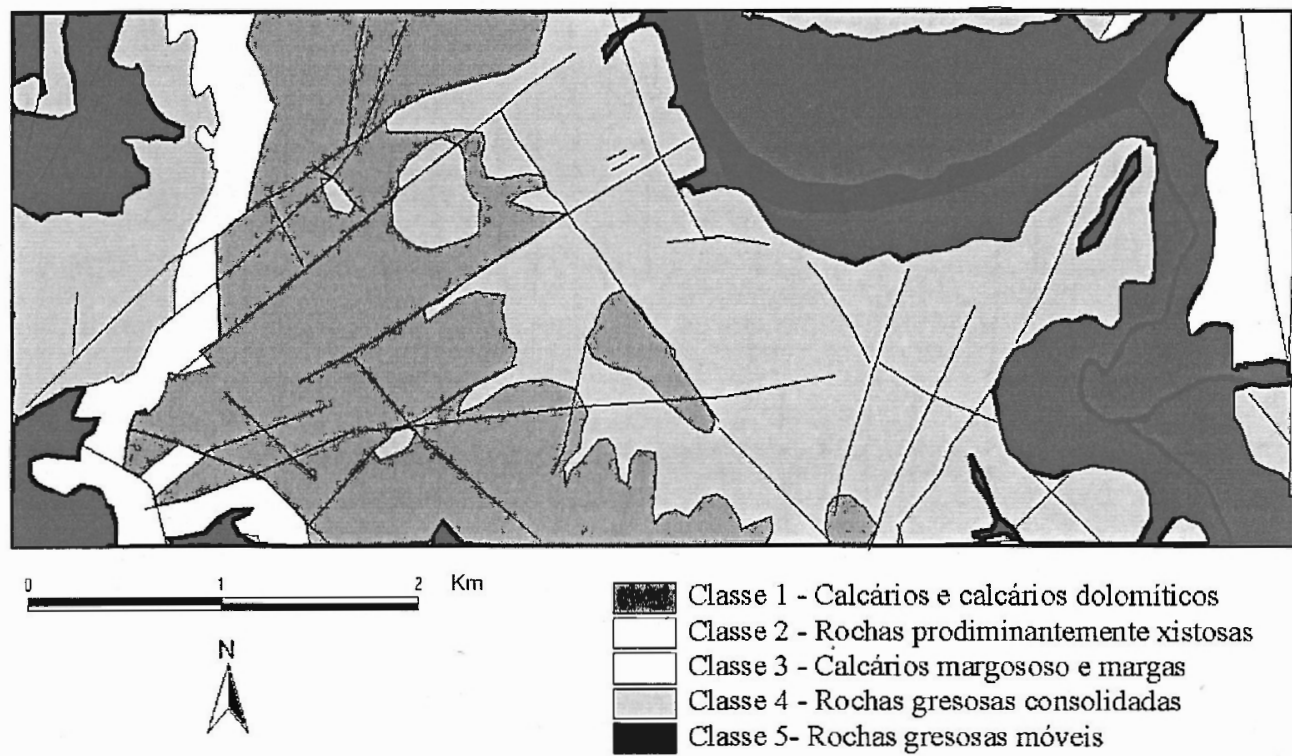

Classe 1 - Calcários e calcários dolomiticos Classe 2 - Rochas prodiminantemente xistosas Classe 3 - Calcários margososo e margas Classe 4 - Rochas gresosas consolidadas Classe 5- Rochas gresosas móveis

Fig. 4 - Classes litológicas da área em estudo

Também para a cartografia de uso do solo, extraído e apenas muito ligeiramente adaptado do levantamento digital efectuado pelo CNIG em 1995, foi necessário proceder a um agrupamento dado o elevado número de classes de uso consideradas (mais de duas dezenas, apenas nos $18 \mathrm{Km}^{2}$ da área considerada).
Neste caso foram consideradas quatro grandes grupos para o uso do solo (fig. 5): áreas florestais que ocupam cerca de $37 \%$ da área, áreas com cobertura arbustiva e herbácea (4\%), áreas com utilização agrícola (a mais representada, com $45 \%$ da área) e áreas construídas ou de uso social (14\%).

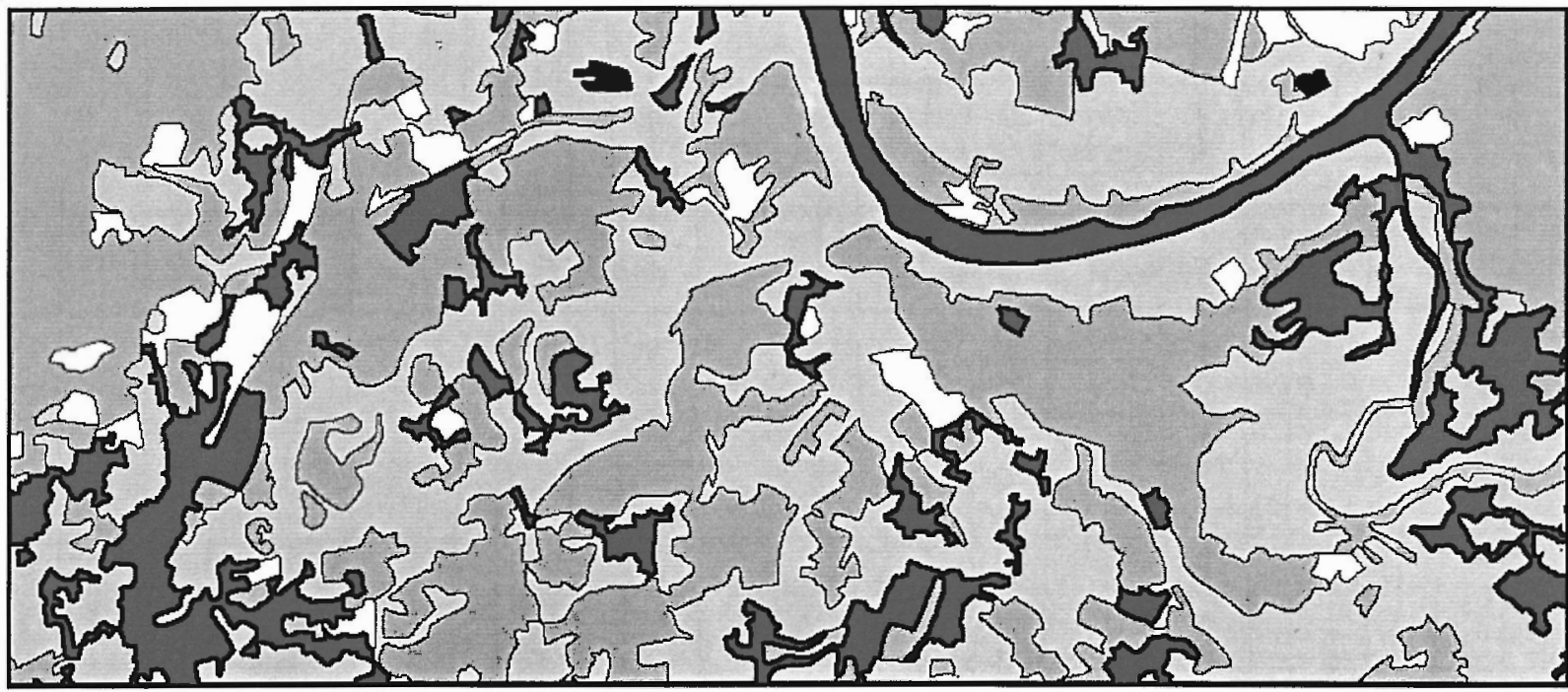

Classe 1 - Áreas florestais

Classe 2 - Áreas de cobertura arbustiva e herbácea Classe 3 - Áreas agrícolas

Classe 4 - Áreas urbanas

Fig. 5 - Classes de uso do solo na área em estudo 
Independentemente da selecção dos factores condicionantes e dos métodos qualitativos ou quantitativos a usar, as escolhas atrás referidas colocam alguns outros problemas.

Em primeiro lugar, o estabelecimento de classes dentro de cada um destes factores. Se para alguns factores, como por exemplo, para os tipos de ocupação do solo, parece lógico o agrupamento de classes aparentemente com comportamentos similares (exemplo: a inclusão numa mesma classe de uso florestal da cobertura florestal de pinheiro, eucalipto, sobreiro, castanheiro ou mista), para outros factores em que se regista uma variação contínua dos seus valores, uma distribuição em classes não deixa de colocar problemas delicados, quase sempre presos ao conceito de limiar. É o caso das classes de declive e dos limites considerados nos 5,15 e $30^{\circ}$.

Depois, é o problema dos pesos com que cada classe e cada factor entram no modelo. Uma questão importante está na necessidade de isolar a influência de cada um dos factores, o que parece difícil num sistema complexo, em que os diferentes factores não actuam isolados, antes interagem no condicionamento dos movimentos. Por exemplo, na área em análise, os declives que se justificam em grande parte pelos condicionalismos estruturais e litológicos vão, por sua vez, condicionar a utilização do solo, pelo menos quando se trata de declives elevados.

\section{O método empírico/qualitativo}

Iniciámos este exercício cartográfico pela construção de um mapa síntese de acordo com as ponderações indicadas na fig. 6. Depois de escolhidas as classes para cada um dos factores e de atribuída uma ponderação de 0 a 3 , em função do presumível significado que cada uma delas teria no condicionamento dos movimentos, foi estabelecida uma fórmula também empírica que relaciona os três factores, dando pesos progressivamente maiores à ocupação do solo, à litologia e aos declives. O mapa resultante (fig. 7), em que se definem três classes de risco, revela uma boa adequação aos movimentos registados no Inverno de 2000/2001, como se pode ver, de modo simples, através do quadro que se inclui na mesma figura.

\section{O método estatístico-quantitativo}

Numa tentativa de aprofundar o modelo e de tentar estabelecer algumas relações matemáticas entre os vários factores, as classes neles definidas e a ocorrência de movimentos de materiais nas vertentes da área, utilizamos os procedimentos esquematizados na fig. 8. Um primeiro problema resulta da já referida interacção dos factores em jogo. Aceitando o factor

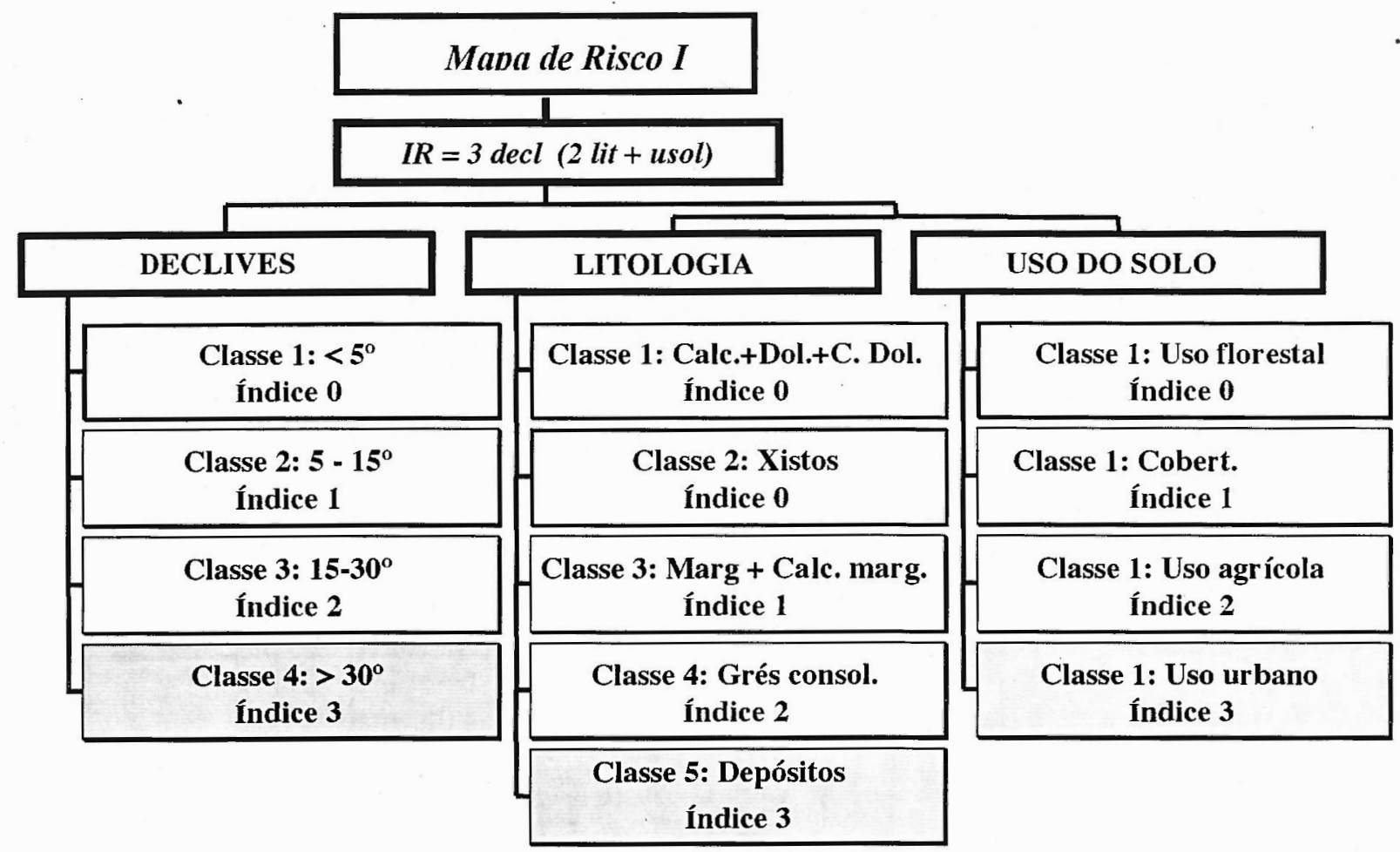

Fig. 6 - Esquema para a metodologia heurística-qualitativa 


\section{Mapa de Riscos I (ponderação empírica)}

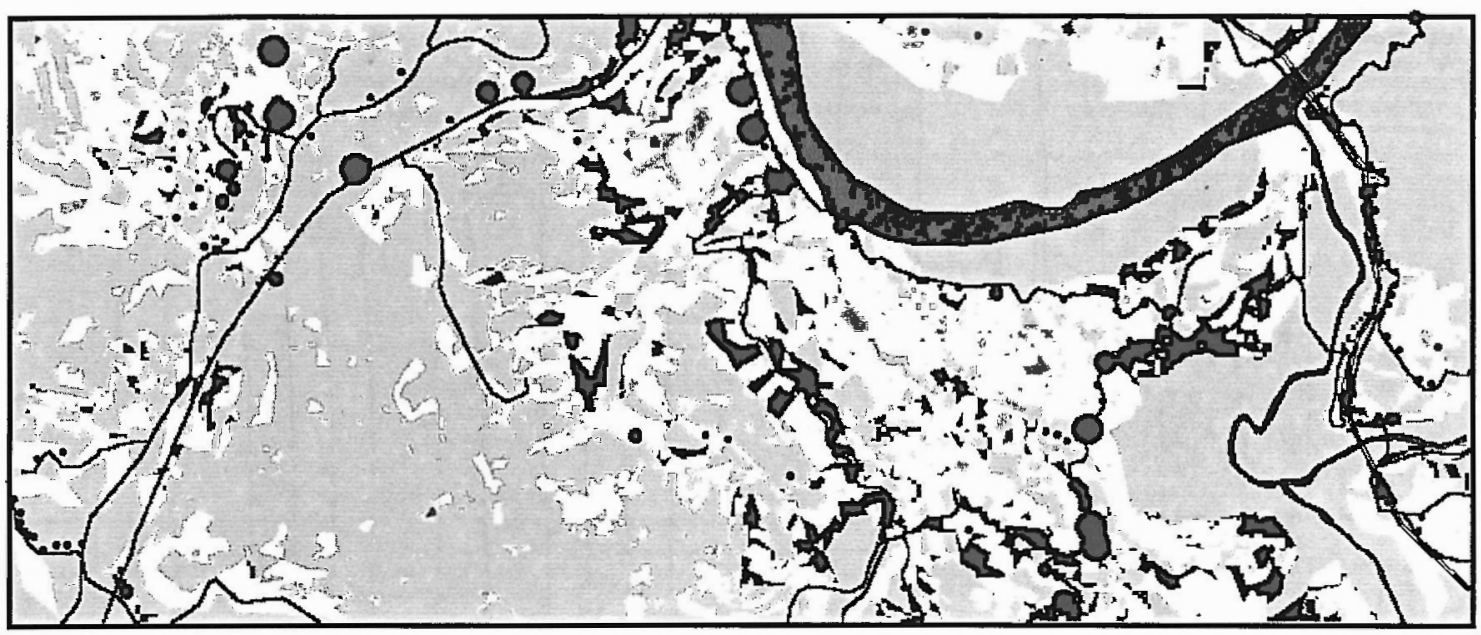

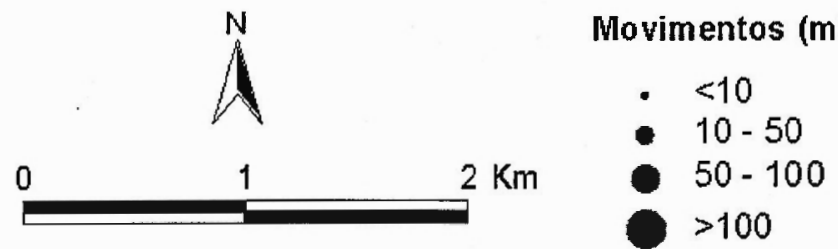

Fig. 7 - Classes de risco (metodologia heurística-qualitativa) e repartição dos movimentos na área em estudo
Risco baixo (fraca prob. de danos)

Risco médio (prob. pequenos danos)

Risco alto (prob. prejuizos elevados)

\begin{tabular}{|l|c|}
\hline 1 - Risco baixo & Mov/Km2 \\
2 - Risco médio & 4 \\
3 - Risco elevado & 38 \\
\hline
\end{tabular}

declive como o mais importante ${ }^{(7)} \mathrm{e}$ aquele que, por si só, melhor correlação apresenta com os movimentos de vertente (fig. 9), começámos por tentar determinar o peso dos declives na explicação da distribuição espacial dos movimentos. Uma vez que a importância dos outros dois factores, litologia e ocupação do solo, parece traduzir também a importância dos declives ${ }^{8}$, procurámos retirar o peso já explicado

(7) Os declives que determinam as conöições de energia potencial e de energia cinética para os movimentos, estão na dependência da estrutura (litologia e tectónica) e das condições de evoluçãọ geomorfológica e vão, por sua vez, condicionar a própria litologia, ditando os locais de acumulação dos depósitos superficiais e, sobretudo, os modos de ocupação dos solos. Tendo em conta que na área em apreço, a maior parte, para não dizer a totalidade, dos movimentos em vertentes acontecem em áreas de forte intervenção humana (vias de comunicação, taludes para outras construções, socalcos agrícolas,...), também aqui a acção dos declives é fundamental. Com efeito, são eles que, em primeira análise, determinam o número de taludes e de aterros, assim como as suas dimensões e condições de estabilidade.

(8) O que justificaria, por exemplo, o elevado número de movimentos encontrados na classe litológica dos xistos e na classe de ocupação florestal. De facto, são os elevados declives da vertente do Maciço Marginal talhada nos xistos e com ocupação essencialmente florestal que justificam o elevado número de movimentos aqui ocorridos. pelo factor declive nos índices que relacionavam a distribuição do número de movimentos em cada classe litológica e de. ocupação do solo com o número total de movimentos verificados no conjunto da área.

Finalmente foram construídos dois mapas. Num deles associaram-se os vários factores de modo qualitativo, atribuindo, neste caso, ao declive o dobro do peso que foi atribuído à litologia e ao modo de ocupação do solo (fig. 10). Noutro, e na procura de uma aproximação cada vez mais rigorosa do ponto de vista quantitativo, foi utilizado um modelo de regressão múltipla para atribuir os pesos a cada um dos factores (fig. 11).

Comparando os três mapas construídos com a mesma informação, mas com métodos e, consequentemente, pesos e ponderações diferentes para os factores e classes consideradas, a primeira conclusão a tirar é, talvez, a de que todos eles se ajustam relativamente bem à distribuição espacial dos movimentos verificados. Pelo menos é o que se depreende da distribuição espacial do número de movimentos 


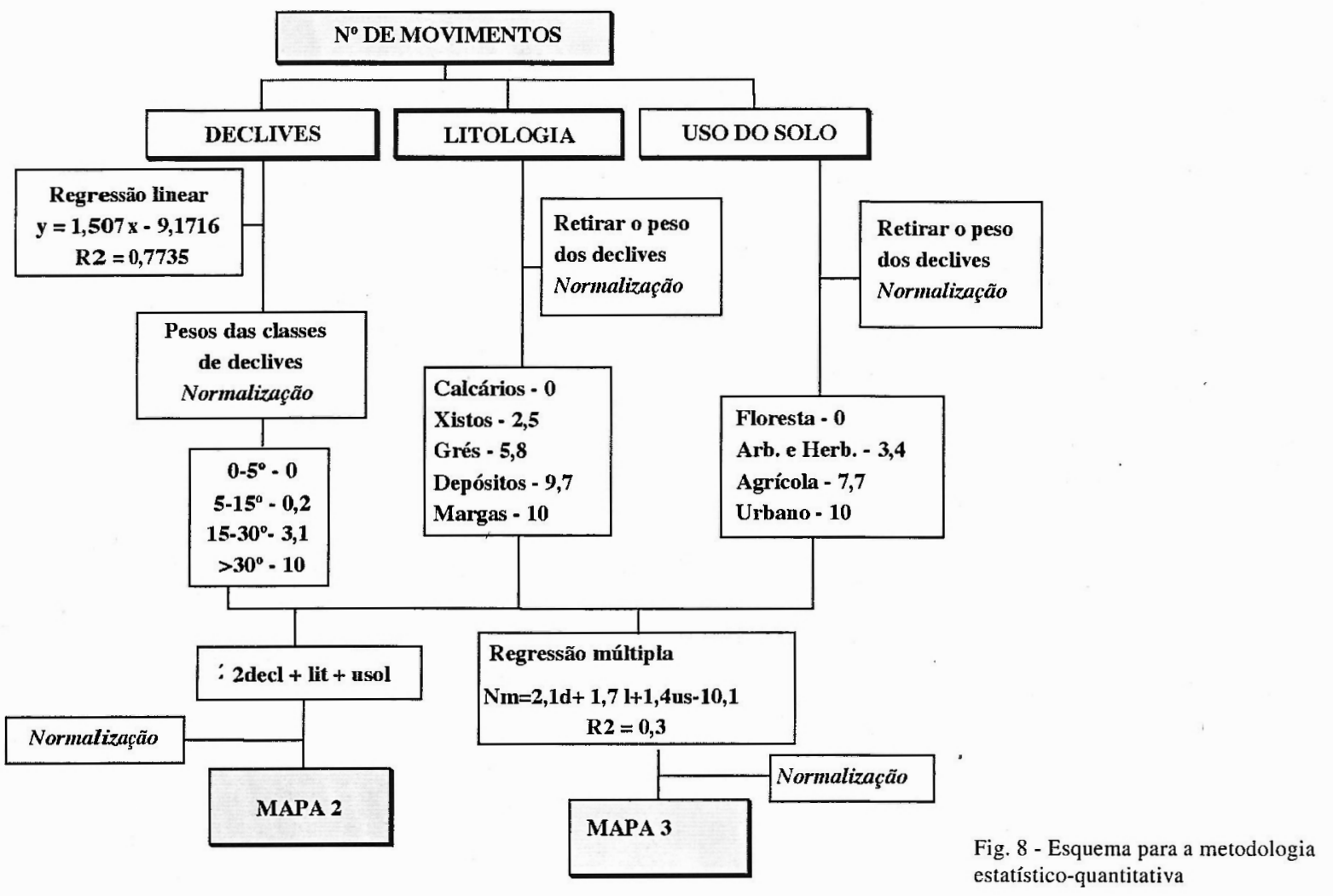

$\mathrm{N}^{\circ}$ (mov.)

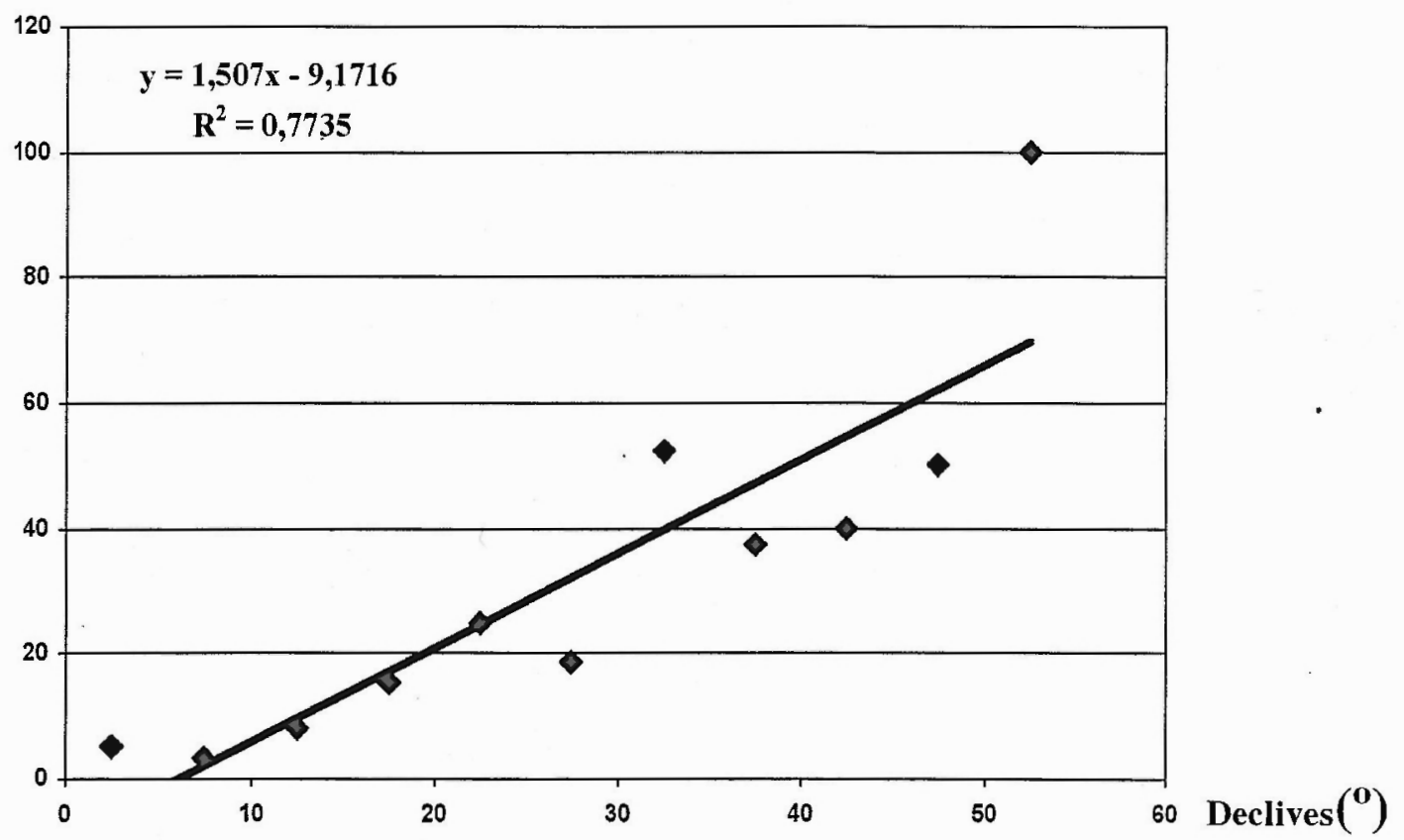

Fig. 9 - Número de movimentos em função dos declives na área em estudo. 

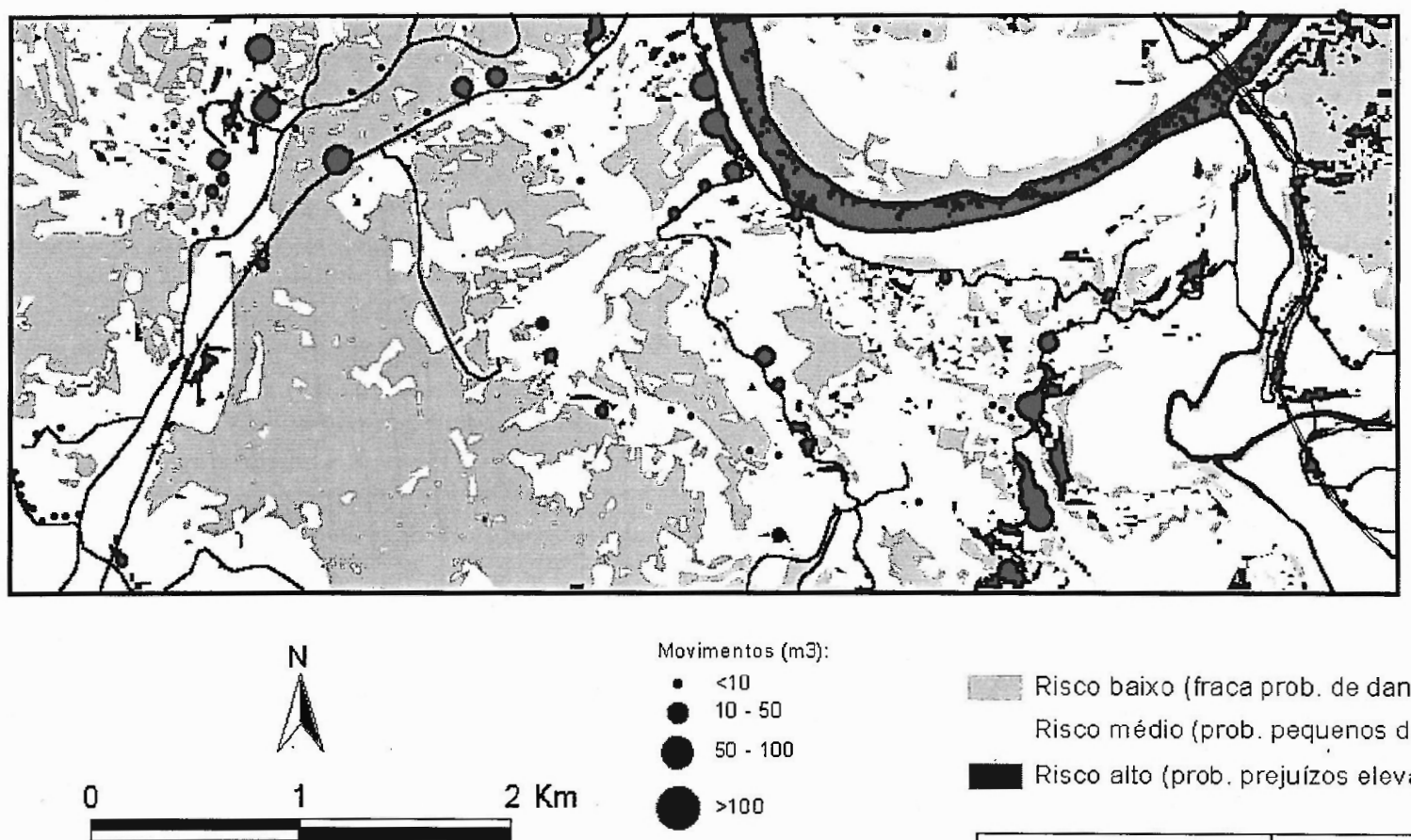

Fig. 11 - Classes de risco (metodologia estatístico-quantitativa - ponderação quantitativa por regressão múltipla) e repartição dos movimentos na área em estudo.

\begin{tabular}{|l|c|}
\hline 1 - Risco baixo & Mov/Km2 \\
2 - Risco médio & 4 \\
3 - Risco elevado & 32 \\
\hline
\end{tabular}
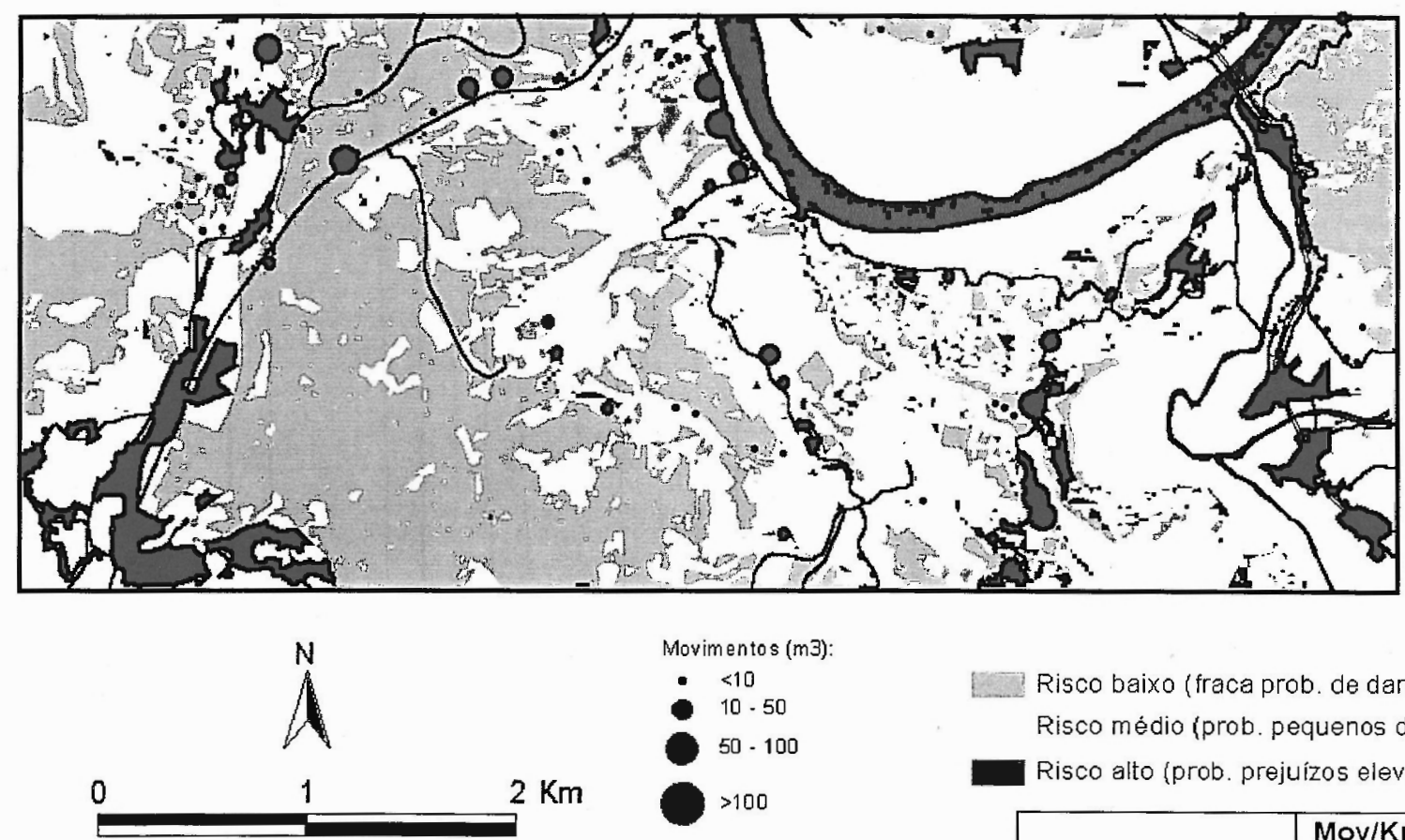

Fig. 10 - Classes de risco (metodologia estatístico-quantitativa - ponderação semi-quantitativa) e repartição dos movimentos na área em estudo. 
por unidade de área em cada uma das três classes de risco consideradas. No entanto, não ficou para nós clara a vantagem da utilização destes métodos de análise quantitativa neste tipo de aproximação.

De qualquer modo, a relativa concordância de resultados através destes três métodos e o seu ajustamento à realidade vivida numa situação de crise como terá sido o Inverno de 2000/2001, aponta em nosso entender, para a validação da cartografia de riscos naturais através da combinação cartográfica dos diferentes factores em presença. Claro que numa aproximação progressiva e numa tentativa de criar um modelo que seja extrapolável para áreas mais vastas a partir de áreas-amostra criteriosamente seleccionadas, de grande utilidade na gestão municipal, será forçosamente necessária a inclusão de outros factores (por exemplo, a tectónica e a forma e dimensão das vertentes) e a análise, com os mesmos passos metodológicos, dos factores de vulnerabilidade das populações (quantitativos de população, tipos de habitação, infra-estruturas, actividades desenvolvidas, valor económico e comercial dos diferentes bens, entre outros).

\section{Conclusão}

Ao longo deste exercício de reflexão sobre as questões ligadas aos riscos naturais, mais especificamente, aos chamados riscos geomorfológicos na região de Coimbra e à utilização de Sistemas de Informação Geográfica para a sua modelização e cartografia, chegámos a algumas poucas conclusões que importa agora sistematizar.

A primeira é a muito conhecida e discutida ideia de que os riscos naturais, ainda que associados a fenómenos regidos pelas leis dos sistemas naturais, não são essencialmente naturais nas suas causas. No caso específico dos movimentos de materiais em vertentes se, de facto, muitos dos factores condicionantes e, particularmente, os factores desencadeantes associados às intensas e persistentes chuvadas do Inverno de 2000-2001, são de ordem essencialmente física, não podemos esquecer que a maior parte dos movimentos e, particularmente, os de maior dimensão e gravidade ocorreram em áreas de intensa intervenção humana (taludes, aterros, socalcos) deixando antever que intervenções mais cuidadosas e mais seguras poderão ajudar a diminuir em muịto alguns dos factores de risco.

A posição de Coimbra, no confronto do Maciço Hespérico com a Orla Mesocenozóica e da "serra" com a "planície", tem reflexos significativos em termos climáticos, geomorfológicos e hidrológicos, logo tem sérias implicações nos fenómenos extremos que configuram os riscos naturais da área, o que levou recentemente F. REBELO(1999) a falar, inclusivamente, na "bacia de riscos" de Coimbra.

No que diz respeito à possibilidade de utilização de Sistemas de Informação Geográfica na criação de modelos explicativos da distribuição espacial de movimentos de materiais em vertentes, logo na cartografia de riscos naturais, verificou-se, apesar de todas as limitações e dúvidas atrás referidas, o(s) método(s) que utilizámos apresenta(m) algum interesse $\mathrm{e}$, mesmo, potencialidades para uma primeira aproximação à cartografia de riscos naturais a escalas que não impliquem grande pormenor $(1 / 25000 ; 1 / 50000)$. Alguma subjectividade e consequente dificuldade na selecção dos factores a tratar e na atribuição empírica ou quantitativa das ponderações, pode ser em parte ultrapassada com um bom conhecimento da dinâmica das vertentes em causa, ou seja com um paciente trabalho de campo. Finalmente, o facto de os mapas criados com recurso a diferentes métodos de ponderação revelarem alguma convergência e mesmo concordância para a maior parte da área cartografada, parece-nos abrir perspectivas para a criação automática de mapas de zonamento de riscos naturais que, a partir de modelos criados para áreas-amostra possam ser extrapolados para áreas mais vastas, o que seria extremamente útil em termos de Ordenamento do Território, numa fase em que as Autarquias se debatem com a revisão dos seus Planos Directores Municipais.

\section{Bibliografia}

ALMEIDA, A. C., SOARES, A. F., CUNHA, L. e MARQUES, J. F. (1990) - "Proémio ao estudo do Baixo Mondego". Biblos, Coimbra, LXVI, pp. 17-47.

CARRARA, A.,CARDINALI, M., GUZETTI, F. eREICHENBACH, P. (1995) - "GIS Technology in mapping landslide hazard". In CARRARA. A. e GUZETTI, F. (ed.) - Geographical Information Systems in Assessing Natural Hazards. Kluwer Academic Publisher, Dordecht, pp. 135-175.

CUNHA, L. e ROCHA, R. (1997) - "Ensino da Geografia e Riscos Naturais. Reflexões a propósito de um mapa de riscos naturais do vale de Coselhas (Coimbra)". Cadernos de Geografia, Coimbra, 16, pp. 25-38.

CUNHA, L. eSOARES, A. F. (1997) - “Alguns problemas geomorfológicos no sector oriental do Baixo Mondego. O confronto de morfologias nas áreas de Coimbra e de Condeixa". Livro de Actas do Seminário O Baixo Mondego - Organização Geossistémica e Recursos Naturais. Coimbra, pp. 41-49.

CUNHA, L., SOARES, A. F., TAVARES, A. e MARQUES, J. F. (1997) - "O «julgamento» geomorfológico de Coimbra. O testemunho dos depósitos quaternários". Cadernos de Geografia, Coimbra, Número especial sobre o I Congresso da Geografia de Coimbra, pp. 14-26. 
CUNHA, Lúcio (1988) - As Serras Calcárias de Condeixa-Sicó-Alvaiázere - Estudo de Geomorfologia. INIC, Col. Geografia Física, 1, Coimbra, $329 \mathrm{p}$.

CUNHA, Lúcio e CRAVIDÃO, Fernanda (2001) - "Territorio, urbanización y calidad medioambiental: una trilogia incompatible?". Actas do Il Encuentro Internacional de Estudios Urbanos, La Habana (no prelo).

DAUPHINÉ, André (2001) - Risques et catastrophes. Observer, spatialiser, comprendre, gérer. Armand Colin, Coll. U, Paris.

DAVEAU, S., BIROT, P. e RIBEIRO, O. (I985/86) - Les Bassins de Lousã et d'Arganil. Recherches, géomorphologiques et sédimentologiques sur le Massif Ancien et sa couverture à l'Est de Coimbra. C. E. G., Memórias, Lisboa, 8.

DAVEAU, Suzanne (coord.); ALMEIDA, Graça; FEIO, Mariano; REBELO, Fernando; SILVA, Rosa F.; e SOBRINHO, A. Sousa (1978) - "Os temporais de Fevereiro/Março de 1978". Finisterra, Lisboa XIII(26), pp. 236-260.

FAUGÈRES, Lucien (1990) - "La dimension des faits et la théorie du risque". Le Risque et la Crise, Malta, Fondation for International Studies, pp. 31-60.

FERREIRA, A. Brum (1992) - "Geomorfologia e Ambiente. Contributo metodológico". Actas do VI Colóquio Ibérico de Geografia, Porto, pp. 1075-1080.

GUZETTI,F.,CARRARA, A., CARDINALI, M. e REICHENBACH, P. (1995) - "Landslide Hazard evaluation : a review of corrent techniques and their application in a multi-scale study, Central Italy". Geomorphology, 31, pp. 181-216.

LOURENÇO, Luciano e LEMOS, Luís (2001) - "Considerações acerca da movimentação em massa ocorrida na vertente poente da Av. Elísio de Moura, em Coimbra". Territorium, Coimbra, 8, pp. 93-112.

MACHADO, João(1999)-Aemergênciados Sistemas de Informação Geográfica na análise e organização do espaço. Textos Universitários de Ciências Sociais e Humanas. FCG e FCT, Lisboa.

MARTINS, Alfredo F. (1940) - O esforço do Homem na Bacia do Mondego. Coimbra, Diss. Licenciatura.

NETO, Pedro, L. (1998) - Sistemas de Informação Geográfica. FCA, Lisboa.

REBELO, Fernando (1985) "Nota sobre o conhecimento geomorfológico da área de Coimbra (Portugal)". Memórias e Noticias, Coimbra, 100, pp. 193-202.

REBELO, Fernando (1995) - "Homes et érosion dans le Centre et le Nord du Portugal. Le cas du Bassin du Mondego". Territorium, Coimbra, 2, pp. 5-10.

REBELO, Fernando (1999) - "A teoria do risco analisada numa perspectiva geográfica". Cadernos de Geografia, Coimbra, 18, p. 3-13.

REBELO, Fernando (2001) - Riscos Naturais e Acção Antrópica, Coimbra, Imprensa da Universidade.
RODRIGUES, Luísa (1998)-Evolução geomorfológica quaternária e dinâmica actual. Aplicações ao Ordenamento do Território - exemplos no Maciço calcário Estremenho. Diss. Doutoramento, Lisboa.

RODRIGUES, R.; BRANDÃO, C. e COSTA, J. P. (200I) "Hidrologia das cheias do Mondego de 26 e 27 de Janeiro de 2001". Relatório do INAG. Direcçãodos Serviços de Recursos Hídricos.

SANCHES, Rui (1996) - O Problema secular do Mondego e a sua resolução. LNEC, Col. Testemunhos, Lisboa.

SANTOS, J. G., CUNHA, L. e FIGUEIREDO, R. (2001) - "Environmental marginality and natural disasters; a case study at Régua (Portugal), in the Douro wine region". UGI. Estocolmo (no prelo).

SANTOS, José Gomes (1996) - A Depressão Marginal. Elementos para a caracterização geomorfológica do sector Coimbra Penela e análise de riscos de movinento de terreno. Diss. Mestrado, Coimbra

SANTOS, José Gomes (2002) - "Movimentos de vertente na área de Peso da Régua: análise e avaliação multi-critério para o zonamento de hazards em ambiente SIG". Territorium, Coimbra, 9.

SOARES, A.F. (1990)- "A Apontamentos sobre a geologia de Coimbra". Livro de Homenagem a Carlos Romariz, Lisboa, pp. 310-331.

SOARES, A. F. ; MARQUES, J. F. E ROCHA, R. B. (1985) "Contribuição para o conhecimento geológico de Coimbra". Memórias e Noticias, Coimbra, 100, pp. 41-71.

TAVARES, Alexandre (1999) - Condicionalismos fisicos ao planeamento. Análise da susceptibilidade no espaço do concelho de Coimbra. Diss. Doutoramento, Coimbra.

TELES, Virgínia (2001) - "Riscos naturais e sociedade. Estudo de caso no concelho de Braga". Territorium, Coimbra, 8, pp. 77-92.

Van WESTEN, C. J. (1998) - Hazard, vulnerability and risk analysis. Prediction of occurrence of slope instability phenomena through GIS based hazard zonation. International Institute for Aerospace Survey and Earth Sciences, Enschede.

YIN, K. L. e YAN, T. Z. (1988) - "Statistical prediction models for slope instability of metamorphosed rocks". In BONNARD, C. (ed.), Landslides, Proceedings of the $5^{\text {th }}$ International Symposium on Landslides, Lausanne, 1988, Balkema, Rotterdam. 2, pp. 1269-1272

ZÊZERE, I. Luís (1997) - Movimentos de vertente e perigosidade geomorfológica na região a Norte de Lisboa. Diss. Doutoramento, Lisboa.

ZÊZERE, J. Luís (2001) - "A avaliação da perigosidade geomorfológica. Aplicação do método de valor informativo na área-amostra de Calhandriz". Livro de Homenagem a Gaspar Soares de Carvalho, Braga, pp. 347-361.

ZÊZERE, J. Luís (2001) - Distribuição e ritmo dos movimentos de vertente na região a Norte de Lisboa. C. E. G., Relatórios da Área de Geografia Física e Ambiente, Lisboa, 8. 
